\title{
SPACE AS
}

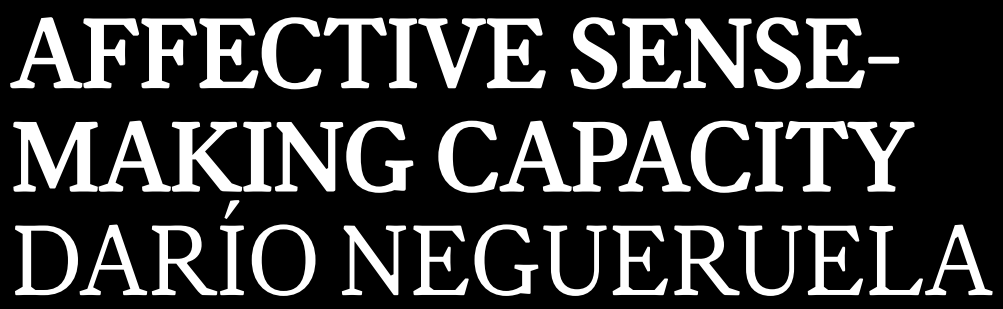

DEL CASTILLO

DARÍO NEGUERUELA DEL CASTILLO. Docteur ès sciences/PhD. EPFL. An architect and researcher from Madrid and currently established in Switzerland, Darío was Head of Research at ALICE lab (École polytechnique fédérale de Lausanne, Switzerland), until March 20r9. Currently, he is the Academic Coordinator of the new Zurich Centre for Digital Visual Studies, UZH-MPG (start Sept. 2019). In 2017, Darío completed his PhD thesis entitled The City of Extended Emotions, addressing the mutually constitutive dynamics between space and collective agency. More precisely, the research looks into the way urban space enacts collective agency (social movements) through affect and emotion and how, in turn, these agencies modify and produce new space. His academic parcours includes a Diploma of Advanced Studies (DEA) from Madrid School of Architecture (ETSAM, Universidad Politécnica de Madrid), an MSc. in Architecture and Urban Design from TU Delft, the Netherlands, and a Bachelor of Architecture and Urban Design from the University of Westminster London, U.K. 
In this essay I argue that the interactive, spatio-relational and necessarily socio-participatory nature commonly thought of for any communicative process must be extended and applied to cognitive processes in urban settings. To what degree can we consider the interactive, cumulative and interrelated patterns of bodily movements, displacements and other essentially socio-spatial practices as the substrate upon which social collective spatial meaning is built? New paradigms in cognitive sciences postulate that the physical modes of interaction constitute not just the limit of a given communicative process, but the very structure that determines the way in which we come to construct and fix meaning. In a converging manner, understanding space as 'a capacity' from the entry point of action and practice, we come to the conclusion that the spatial dimension strongly influences the interaction process through which sense-making is enacted. This very idea carries relevant consequences for our shared reflection on the architectonics of communication. For instance, distinctions between cognizing and feeling need to be revised in the context of embodied sense-making. This is of accrued relevance for reformulating urban cognition and the emergence of new forms of space making sociality. Finally, I consider whether this line of reflection and research may allow us to link and relate particular epistemological frameworks and paradigms previously thought to be mutually exclusive.

\section{INTRODUCTION:}

\section{SPACE AS THE AGENTIAL SUBSTRATE OF SOCIAL INTERACTION}

How do we enact, derive or build meaning of and in our cities? In this brief essay, I want to elaborate on a path, which, delving into various different theoretical origins, points towards a constructive and emergent stance on urban cognition. My intention here is to argue for the consideration of the constitutive and intertwined role of the affective and spatial dimensions in any cognitive process of the city (and, perhaps, the urban condition). To that aim, I depart from an understanding of space consisting of mere definitions of space as either physical metric distance or as location, and seek to reconstruct its agential capacities. This, I argue, can prove operational for further involving the concourse of affect in how we mobilize and enact architectures of sociality in the contemporary city.

Our material, bodily and situated perspective opens the door to this particular narrative. Social interaction, if considered as one of the bases for the constitution of any social sphere, certainly requires minimum doses of mutual understanding. While much emphasis has been placed on the different forms of verbal communication and their articulation into varied forms of social dialogue, my attention turns here to the spatial and bodily dimensions of social interactions as a 
basis for the cognitive. Physical co-presence can amount to more than the simple possibility of non-verbal interpersonal communication in the form of visually remarking behaviour of others. Indeed, the ways in which bodies resonate with other bodies are varied. Bodies register, assess, interpret, vibrate and feel. Space has long been a suspect in all things social and it has been speculated that it plays a protagonist role in those environments, like our cities, where most social, economic and cultural innovations tend to occur. Authors from a diversity of backgrounds and approaches have recognized that the very spatial dimension of cities structures, in fact, our social interactions ${ }^{1}$. From the lively but yet distant conversations in a street market to the moments of intimacy in a restaurant, the regimes of engaging with the world emerge from their non-trivial bodily substrate. And those interactions are the substance of our regimes of sociality. Recurrent and still relevant concepts like Gemeinschaft and Gesellschaft ${ }^{2}$ elaborate on the consequences of such modalities of encounter, favoured or constrained by the dense and artificial environments where we spend most of our lives.

Alternatively, the heterogeneity that is assumed or desired as the quintessential urban quality is key in opening up the horizon of future possibilities. Alterity and heterogeneity in our environment seem intimately related to the plurality we need in our societies in order to avoid the dangers of post-political demagogy. In this respect, I consider the presence of the Other as the crucial substrate of any societal endeavour.

\section{INTERPRETATIONAL DRIVE AND AFFECTIVE ENACTMENT OF MEANING}

What can, then, be the role of affect in all of this? I propose two key elements for the lucubration on the role of affect in what previously has been considered the reconstruction and ultimate understanding of these communicative situations by means of reasoning or 'cold' cognitive abilities. First, the unavoidable presence of the affective dimension as constitutive of any appraisal, any perception, any enactment of a

I See, for instance, sources as varied as: Vinicius M. Netto, The Social Fabric of Cities (Abingdon: Routledge, 20I6); Jacques Levy, 'Penser la ville: un imperatif sous toutes les latitudes', Cahiers d'études sur la Méditerranée orientale et le monde turco-iranien, I997 <https://cemoti.revues.org/I458> [accessed I7 August 20I7]; Jane Jacobs, The Death and Life of Great American Cities (New York: Vintage Books, 196r); Martina Löw and Donald Goodwin, The Sociology of Space: Materiality, Social Structures, and Action, Cultural Sociology (New York: Palgrave Macmillan, 2016).

2 Concepts reflecting different social structure through their basis on either affiliation of kind and resemblance or on complementary interest, or mechanical and organic solidarity as Durkheim would put it. Émile Durkheim, The Elementary Forms of the Religious Life, ed. by Mark Sydney Cladis, trans. by Carol Cosman, Originally published in I9I2 (Oxford: Oxford University Press, 2001). 
worldview ${ }^{3}$. Second, the less explored idea of emotions as interpretative evaluations that may come to complement and extend appraisal and enactive theories of emotion.

Within current emotion research, a wide array of appraisal theories posit that affective phenomena are, in essence, the result of the shortcut evaluation of a perceived stimulus, sometimes complementing and sometimes contradicting our higher cognitive reasoning. In this stream of emotion theory and research, this assumption performs a timely overturn, allowing us to scrap the pejorative tarnish of sentimentality, hysteria and weakness that has often accompanied emotions in our cultural and scientific models.

The postulations of affect as evaluative judgements proper speak of the synthetic interpretative performativity of emotion and affect ${ }^{4}$. They emerge from the most immediate confrontation with our situation in the world and, as such, constitute the most direct appraisal of 'apparent reality'. ${ }^{5}$ The essential power of emotions as synthetic interpretative evaluations of such apparent reality is evident in the fact that they are elicited by composites that pertain to different degrees of complexity. While the interpretative work involved might vary greatly between, say, the perception of a spider and the perception of the collapse of a financial system, emotions always perform meaning. ${ }^{6}$ In a social context like the city, such apparent reality is configured not only by the appraisal of what environmental events are in themselves, but most importantly of what the actions and expressions of others might mean for our well-being.

Communication is made possible through substitutions, allowing for an endless process of recoding and articulation. If we are to believe that emotional and affective behaviour and expression constitute a basic and non-substitutable channel of communication among individuals (as many scholars argue that emotions are actually and foremost intended at social communication ${ }^{7}$ ), does this need to rearticulate, to

3 As postulated by and further developed by enactive approaches to affectivity (e.g. Giovanna Colombetti and Evan Thompson, ' 3 the Feeling Body: Toward an Enactive Approach to Emotion', in Developmental Perspectives on Embodiment and Consciousness (New York: Lawrence Erlbaum, 2008), 45-68; Giovanna Colombetti and Joel Krueger, 'Scaffoldings of the Affective Mind', Philosophical Psychology, 28.8 (2014), I157-76 <https://doi.org/ro.1o 8o/o9515089.2014.976334>; Daniel D. Hutto, 'Truly Enactive Emotion', Emotion Review, 4.2 (2012), I76-8I <https://doi.org/Io.1177/1754073911430134>.

4 Martha C. Nussbaum, 'Emotions as Judgments of Value and Importance', in Thinking About Feeling: Contemporary Philosophers on Emotions, ed. by Robert C. Solomon (Oxford: Oxford University Press, 2004).

5 Nico H. Frijda, The Emotions (Cambridge: Cambridge University Press, 1986).

6 To an extent to which the epistemology of emotions claims they are meanings in themselves.

7 See for instance, the argumentation about the rethorical nature of emotion in in Daniel M. Gross, 'Introduction Being-Moved: The Pathos of Heidegger's Rhetorical Ontology', in Heidegger and Rhetoric, ed. by Daniel M. Gross and Ansgar Kemmann (Albany: State University of New York Press, 2005) <http://www.sunypress.edu/ pdf/6ri67.pdf > [accessed 22 February 2017]. 
interpret also happen with emotion? Do we need to interpret a set of symbolic cues that signal an appraisal of something which is no longer there, which is absent? If so, social interaction, as based upon all possible forms of communication, needs to be regarded as an act of constant emotional interpretation (in both meanings of performance and decoding) of our eventful contexts.

This implies that our situatedness in a populated heterogeneous and plural world demands a work of constant interpretation, which seems to be more the working grounds of a reflexive approach than one concerned merely with impersonal and purely technical decoding. Moreover, it might imply a constant generation of new meanings, new interpretations. The reunion of the active and enactive dimensions of affect with such unavoidable interpretational dimension perhaps leads us to reconsider such practice of emotions as essentially a rhetorical art in the sense implied by Daniel M. Gross and close to original Aristotelian postulates. ${ }^{8}$ The importance of this appraisal/interpretation resides in its essentially agential nature. The very capacities of an agent, meaning her horizon of possibilities, are sketched by her enacted construction of a worldview, which in turn, give a measure of its constitutive situatedness.

These views are, of course, not new nor strictly mine. The original sketch of agency laid out by Maturana and Varela ${ }^{9}$ in their theory of autopoiesis, anchors agency in the interactive situatedness of the organism, which by means of its emergence through organizational closure also make sense of its environment and its changing conditions. As such, the concept of agency put forward by autopoiesis is not, thus, grounded in a pre-existing élan vital ${ }^{\mathrm{I}}$, but simply emerges out of the interaction with materially bounded elements. Moreover, this lays the first stone upon which the enactive approach proper would develop its ideas, bridging the divide between previously distinctively theorized areas of perception and cognition (appraisal). Varela, Thompson, and Rosch, defined this novel approach in the following manner: "the enactive approach consists of two points: (I) perception consists in perceptually guided action and (2) cognitive structures emerge from the recurrent sensorimotor patterns that enable action to be perceptually guided."

8 Ibid

9 F.G. Varela, H.R. Maturana, and R. Uribe, 'Autopoiesis: The Organization of Living Systems, Its Characterization and a Model', Biosystems, 5.4 (I974), I $87-96<$ https:// doi.org/10.1016/0303-2647(74)90031-8>; Humberto R. Maturana and F. J. Varela, Autopoiesis and Cognition: The Realization of the Living (New York: Springer, 1980).

Io Henri Bergson, L'Évolution Créatrice (Paris: Félix Alcan, 1907).

II Varela, Thompson, \& Rosch, The Embodied Mind: Cognitive Science and Human Experience. (Cambridge, MA: MIT Press, I99I), I73 
In order to figure out how this might be helpful in our endeavour, let us now return to the city and the problem of making sense of it all. The consideration of the question of cognition has, since the beginning of the modern social thought, been postulated around one of the foundational problems of sociology and the social sciences. Agency and structure ${ }^{\mathrm{I2}}$, best exemplified by Simmel's reflection on the loss of individual agency as the main problem of city life, in the initial passages of his Mental life and the Metropolis. ${ }^{13}$ I propose, moreover, that it is crucial to reconsider the role of space in the relation between all those expressions of emotion that are in fact absent and the process of interpretation.

The problem is manifold, but it certainly involves the regulation and filtering of modes of co-presence, and perhaps more importantly of coexistence of diversity. Such is the case when urban form is actively regulating modes of human interaction that have relevant outcomes. For instance, in many urban protests, the urban space regulates the probabilities that those claims will be witnessed by local populations, those living in that particular neighbourhood, or by those actually passing by on their way to their job or school or simply visiting, or, rather, by a mixture of those. This regulation of different modes of co-presence can help the actions of a group reach a particular potential of exposure to otherness, and extimacy. ${ }^{{ }^{14}}$ The spatialized interaction between those diverse and different, yet proximal, realities is what engenders the richness and multiplicity of meanings from which different agencies are born. Thus, the urban would seem to have a say in the constitution of a shared framing of our experience. This observation belongs to the line of reflection that grants cities qualities well above and beyond the mere container for our actions, ranging from the aggregated effect, as cities often "represent the possibility of weaving our actions into complex associations" ${ }^{15}$ to the capacity of citenvironment and fate, based on an understanding of free will. On the other, the constraints that our environment, be it through physical material dimension or through values, beliefs, norms and rules arising from social institutions, exert upon humans, conditioning their capacities and delimiting their freedom to think, to choose, to act.

I3 "The deepest problems of modern life flow from the attempt of the individual to maintain the independence and individuality of his existence against the sovereign powers of society, against historical heritage's weight and the external culture and technique of life. This antagonism represents the most modern form of the conflict which primitive man must carry on with nature for his own bodily existence," Georg Simmel, Mental Life and the Metropolis, trans. Kurt Wolff (New York: Free Press, I950 [1902]).

I4 David Pavón-Cuéllar, 'Extimacy', in Encyclopedia of Critical Psychology (New York: Springer, 20I4), 66I-664 <http://link.springer.com/Io.1007/978-I-46I4-5583-7_Io6> [accessed 23 January 20I7].

I5 Netto, The Social Fabric of Cities. 
ies, as elaborate artefacts, to qualitatively change the communication performed by our social interactions. ${ }^{16}$

In addition, situated engagement can be said to "encourage noisy and unruly engagement in situated, material, discursive and conceptual places." ${ }^{17}$ It therefore requires a particular ethical opening up, in coherence with the Levinasian notion of 'situated availability' ${ }^{\mathrm{r} 8}$, as well as a decanted projective capacity. ${ }^{19}$ Accordingly, this view of agency grants importance to socio-spatial modalities of interaction, and sees them inscribed in a non-trivial time dimension. In other words, it seeks to actualize agency as a temporally embedded process of social and spatial engagement that engenders a 'reciprocity of perspectives'..$^{\circ}$ In practical terms, it means that the spatial configuration can be seen now as constitutive of human individual and collective agency, and not as mere crystallization of institutional 'structural' constraints.

\section{COLOPHON: SPACE AS AFFECTIVE (AGENTIAL) CAPACITY.}

If we follow the line of reasoning proposed here above, we come to recognize that we build our worlds not only through an appraisal of a fixed and flat state, but rather through a tentative affective interpretation of what our surrounding material interactions might mean. This is the case as our surroundings do not just cause us pain or happiness for their intrinsic qualities or content, only assess our environment, including the events that give it shape and duration in time. For instance, one's feeling of frustration and perhaps even anger when trapped in rush hour, has not only to do with the fact of being stuck in the car or in an overcrowded metro wagon, but most importantly with the consequences we infer this condition has for our following material interactions, even for a whole lifestyle and thus, for our well-being and those around us. Or, in other words, via the enactment of multiple futures. We navigate this field of uncertainty through contingent and emergent meaning, requiring the concourse of all. The implications of this are multiple, but perhaps the

I6 Juval Portugali, Complexity, Cognition and the City (New York: Springer Science \& Business Media, 2011).

I7 Deborah Bird Rose, 'Indigenous Ecologies and an Ethic of Connection', in Global Ethics and Environment, ed. by Nicholas Low (London: Taylor \& Francis, 2002), 13 <https:// doi.org/ro.4324/9780203015254-17>.

I8 Ibid.

I9 "Such approach informed by the past (in its 'iterational' or habitual aspect) but also oriented toward(s) the future (as a 'projective' capacity to imagine alternative possibilities) and toward(s) the present (as a 'practical- evaluative' capacity to contextualize past habits and future projects within the contingencies of the moment)" Mustafa Emirbayer and Ann Mische, 'What Is Agency?', American Journal of Sociology, 103.4 (1998), 962-1023 <https://doi.org/ro.1086/231294>.

20 Alfred Schutz and Thomas Luckmann, The Structures of the Life-World, Northwestern University Studies in Phenomenology \& Existential Philosophy (Evanston, IL: Northwestern University Press, 1973), 6o-68. 
most important, in my opinion, is the radical call for an inherent welcoming of the collective contingency of meaning through co-presence, should we still believe that the urban holds an emancipatory promise. ${ }^{2 \mathrm{I}}$

It is important to stress that the notion of space as interpretative passion that I intend to put forward understands space as something produced through its practice ${ }^{22}$, and not as a pre-given datum. What emerges is a view of (urban) space as enacted and invested by the endless becoming of human material interactions. A view that sees space engendered by myriad exchanges that give birth to and result from our contingent trajectories and which, also produce new relational dimensions insofar as they are felt, interpreted and cognized. And such becoming is translated in the agential capacities of matter, epitomized by higher complexity living forms, like ourselves. To put it differently, I propose space to be read in relation to what Solomon ${ }^{23}$, echoing ancient wisdom, has captured by his enunciation of the 'passions' (that which makes us do, what drives our lives). In this respect, space pertains to a complex nature. It does not only influence the results of our interpretative emotional appraisal, it is enacted through our very emoting, which raises, in intellectual terms, the question of whether the city can indeed set us free.

Alberto Corsín Jiménez, 'On Space as a Capacity', Jroyaanthinst The Journal of the Royal Anthropological Institute, 9.I (2003), I37-53; Mathis Stock, 'Spatial practices, theoretical implications', Revue électronique des sciences humaines et sociales, (2015). <http://www.espacestemps.net/articles/spatial-practices-theoretical-implications/> [accessed I4 March 2016].

Hackett Pub. Co, I993). 

